\title{
The fluctuant nature of precipitating antibodies in dairy farmers
}

\author{
YVON CORMIER, JACQUES BÉLANGER \\ From l'Unité de Recherche, Centre de Pneumologie, Hôpital Laval, Sainte-Foy, Quebec, Canada
}

\begin{abstract}
Four hundred and forty five of 888 dairy farmers studied in an epidemiological survey four years previously were restudied to determine change in precipitins and in clinical features. Subjects answered the same questionnaire, which was filled in by the same nurse in the same winter months, and had blood withdrawn for precipitin analysis (double diffusion technique). Of the 445 subjects retested, $48(10.8 \%)$ had been precipitin positive at the first study; of these, 34 remained positive four years later and 14 had reverted to negative. Twenty eight subjects previously negative for precipitins had become positive, so that 62 subjects in all were precipitin positive when restudied $(13.9 \%)$. Of the 445 farmers, 369 were precipitin negative at both studies. The prevalence of symptoms, including cough, sputum production, wheezing, dyspnoea, and fever and chills, was similar for subjects who were consistently negative for precipitins and consistently positive and for those who changed from one to the other. Only one subject developed farmer's lung; he had precipitins in both studies. This study shows a fluctuation in the precipitin state of dairy farmers, suggesting that more farmers have precipitins at least once in their lifetime than are identified by screening at a single point in time. Relatively few develop farmer's lung or other respiratory symptoms. The presence of precipitins in a symptomless farmer appears to have no clinical importance.
\end{abstract}

\section{Introduction}

We recently reported the results of an epidemiological survey on the prevalence of serum precipitins and the factors influencing their development in Quebec dairy farmers. 'The prevalence of positive reactions with the double diffusion technique of Ouchterlony ${ }^{2}$ was $8 \cdot 4 \%$, similar to that in other published studies, ${ }^{34}$ particularly one carried out nearby in Vermont in the United States. ${ }^{5}$ Although several studies have looked at the prevalence of precipitins and the relation of precipitins to lung disease, ${ }^{6-9}$ the long term outcome of patients positive for precipitins and the variation in precipitin state with time are less clearly defined. Previous studies have suggested that farmers with precipitins were more likely to have respiratory disability than those without precipitins, ${ }^{910}$ though in one study pulmonary function did not differ between subjects with and without precipitins."

Precipitins are usually present in farmers with acute

Address for reprint requests: Dr Yvon Cormier, Hôpital Laval, 2725 chemin Ste-Foy, Ste-Foy, Quebec, Canada GIV 4G5.

Accepted 8 March 1989 farmer's lung, ${ }^{12}$ though their pathogenetic role is open to question ${ }^{1314}$ and it is not clear whether their presence is a prerequisite for the development of acute disease. A large proportion of symptomless dairy farmers and bird fanciers positive for precipitins have lymphocytic alveolitis, ${ }^{1516}$ and this may persist for at least two years in the absence of symptoms. ${ }^{17}$ How many of those with precipitins or alveolitis eventually develop an episode of extrinsic allergic alveolitis is unknown, nor is it known whether lymphocytic alveolitis always precedes extrinsic allergic alveolitis.

The prevalence of precipitins in the farm population in our previous study was not age dependent, 'suggesting either that precipitins develop at an early age and remain throughout life or that individuals may fluctuate between having and not having precipitins. Other studies, however, have reported a higher prevalence of precipitins in certain age groups. ${ }^{18}$

We therefore set out to repeat the precipitin analysis and questionnaire survey in the 888 farmers who enrolled in our initial study four years ago.' The aims of the present study were: (1) to determine the clinical outcome over four years in relation to precipitin state (for example, development of farmer's lung or res- 
piratory symptoms); (2) to determine whether and to what extent individuals can change from precipitin positive to precipitin negative or the reverse; and (3) to look for environmental and personal factors that might be related to these changes.

\section{Methods}

\section{SUBJECTS AND QUESTIONNAIRE}

The study population consisted of the 888 dairy farmers studied four years previously during the winter (January to March) of 1980 and $1981 .{ }^{i}$ The present study was carried out during the same months of 1984 and 1985, subjects initially enrolled in 1980 being contacted in 1984 and those from 1981 being contacted in 1985. A letter was sent to all subjects indicating that they would be contacted by telephone by the same person as four years previously and would be asked the same questions as in the first study. The questionnaire was based on the American Thoracic Society's standard for an epidemiological survey, ${ }^{19}$ with the addition of specific questions on farming.

\section{PRECIPITIN TESTING}

A prescription form for precipitin analysis was included with the letter, and the subject was asked to go to the nearest health centre for blood to be sampled. Blood was sent to us for precipitin testing by the double diffusion method of Ouchterlony ${ }^{2}$ as in the previous study. Serum was tested against the antigens used previously-Micropolyspora faeni (Faenia rectivirgula) and Thermoactinomyces vulgaris (from Greer Laboratories) and Aspergillus fumigatus (two strains from Greer Laboratories and one from Bencard). As the serum samples from the two studies were not tested simultaneously all possible precautions were taken to minimise technical variations. All analyses were done by the same technique, ${ }^{2}$ by the same technician, in the same laboratory, and with the same source of antigen.

\section{DATA ANALYSIS}

The $\chi^{2}$ test was used to compare the characteristics, determined in 1980-1, of subjects who were restudied with those who were not. Subjects who were restudied were divided into four groups according to whether they did or did not have precipitins in the current and the previous study: group 1 -subjects with precipitins in both studies; group 2-subjects positive in the first study and negative at follow up; group 3-subjects negative in the first study and positive at follow up; and group 4 subjects negative in both studies. Values in the four groups were compared by $\chi^{2}$ test. To test the hypothesis that the precipitin positive subjects were more likely to return to be restudied, McNemar's test was used to compare the numbers of precipitin positive and negative subjects.

\section{Results}

Of the 888 subjects in the initial study, 445 are included in the present report. The subjects not restudied include 133 who had ceased farming, 136 who refused to answer the questionnaire, 10 who could not be contacted, and 15 who had died; of the 594 subjects who answered the questionnaire, 149 did not produce a blood sample for precipitin testing, leaving 445 subjects for analysis. These $\mathbf{4 4 5}$ subjects were similar in smoking habit and size of farm to those who were not restudied but the group contained fewer women $(p<0.001)$ and more subjects in the 35-49 age group $(\mathrm{p}<0.01)$ and the group spent more time in the barn $(p<0.001$ (table 1). More subjects who were precipitin positive than negative in the initial study were restudied $(64 \%$ versus $49 \% ; p<0.05)$. The farm practice of farmers who participated the second time had not changed significantly between the two studies; the variables compared were the size of farm, number of cattle, time spent in the barn, methods of hay making and storage, and use of silos.

Precipitin results are presented in table 2 and titres

Table 1 Comparative data for subjects who were and were not restudied

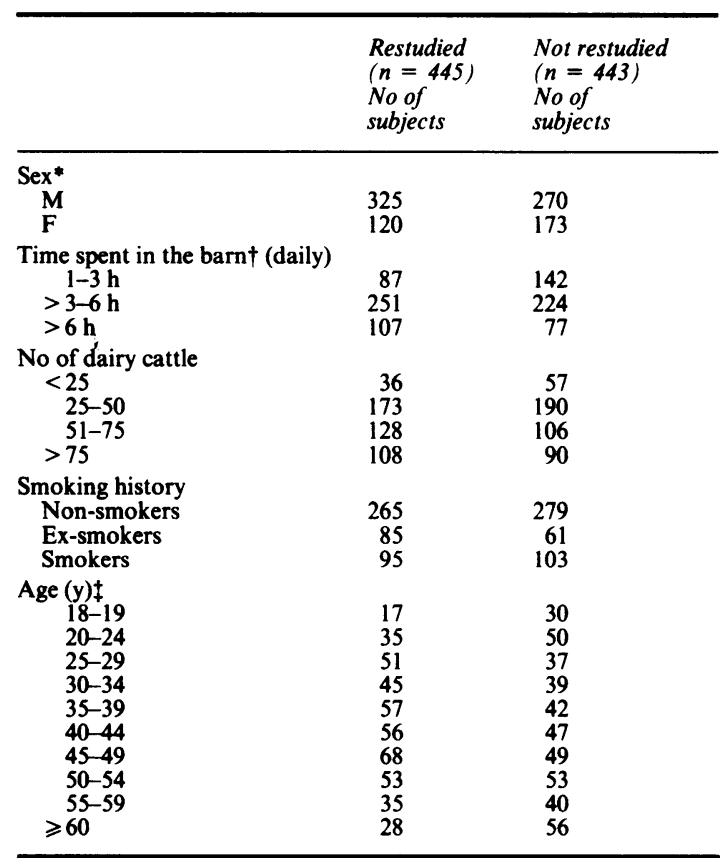

*More males in the restudied group $(p<0.001)$.

† Restudied subjects spent more time in the barn than those of the not restudied group $(\mathrm{p}<0.001)$.

$\ddagger$ More subjects in the age group 35-49 years in the restudied group $(\mathrm{p}<0.01)$. 
Table 2 Distribution of precipitin positive and negative individuals among all restudied subjects at the time of the initial study and the second study

Initial study

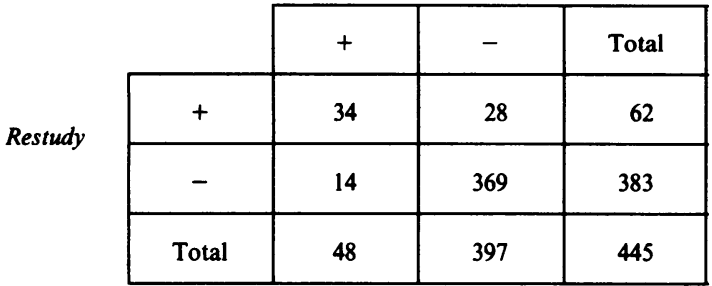

in tables 3 and 4 . Of the $\mathbf{4 4 5}$ subjects retested, $10 \cdot 8 \%$ had had positive precipitins in the initial study compared with $13.9 \%$ in the second study ( $p<0.05$, McNemar's test for significant changes). Of the 48 positive reactions in the initial study, 45 were to $M$ faeni; one subject had a dual reaction to $M$ faeni and $A$ fumigatus and two were positive to $A$ fumigatus alone. Of the 62 positive precipitin reactions at the follow up study, 61 were to $M$ faeni and one to $A$ fumigatus. No reactions to $T$ vulgaris were found. Of the 34 subjects with precipitins in both studies, 33 had antibodies to

Table 3 Precipitin titres: both studies for all subjects who remained positive

\begin{tabular}{|c|c|c|c|c|}
\hline Subject No & Initial & tudy & Follon & \\
\hline $\begin{array}{r}1 \\
2 \\
3 \\
4 \\
5 \\
6 \\
7 \\
8 \\
9 \\
10 \\
11 \\
12 \\
13 \\
14 \\
15 \\
16 \\
17 \\
18 \\
19 \\
20 \\
21 \\
22 \\
23 \\
24 \\
25 \\
26 \\
27 \\
28 \\
29 \\
30 \\
31 \\
32 \\
33 \\
34\end{array}$ & 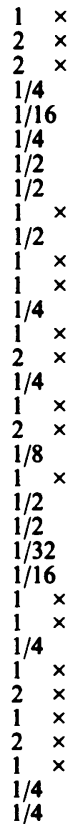 & $\begin{array}{l}\text { MF } \\
\text { Asp } \\
\text { MF } \\
\text { MF } \\
\text { MF } \\
\text { MF } \\
\text { MF } \\
\text { MF } \\
\text { MF } \\
\text { MF } \\
\text { MF } \\
\text { MF } \\
\text { MF } \\
\text { MF } \\
\text { MF } \\
\text { MF } \\
\text { MF } \\
\text { MF } \\
\text { MF } \\
\text { MF } \\
\text { MF } \\
\text { MF } \\
\text { MF } \\
\text { MF } \\
\text { MF } \\
\text { MF } \\
\text { MF } \\
\text { MF } \\
\text { MF } \\
\text { MF } \\
\text { MF } \\
\text { MF } \\
\text { MF } \\
\text { MF }\end{array}$ & 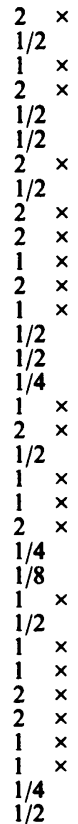 & $\begin{array}{l}\text { MF } \\
\text { MF } \\
\text { MF } \\
\text { MF } \\
\text { MF } \\
\text { MF } \\
\text { MF } \\
\text { MF } \\
\text { MF } \\
\text { MF } \\
\text { MF } \\
\text { MF } \\
\text { MF } \\
\text { MF } \\
\text { MF } \\
\text { MF } \\
\text { MF } \\
\text { MF } \\
\text { MF } \\
\text { MF } \\
\text { MF } \\
\text { MF } \\
\text { MF } \\
\text { MF } \\
\text { MF } \\
\text { MF } \\
\text { MF } \\
\text { MF } \\
\text { MF } \\
\text { MF } \\
\text { MF } \\
\text { MF } \\
\text { MF } \\
\text { MF }\end{array}$ \\
\hline
\end{tabular}

MF-Micropolyspora faeni; Asp-Aspergillus fumigatus.
Table 4 Precipitin titres at the initial study for subjects who had reverted from positive to negative $(P N)$ in the follow up study and for those who had converted from negative to positive (NP)

\begin{tabular}{lc}
\hline $\begin{array}{l}\text { Group } \\
\text { Titre }\end{array}$ & No of subjects \\
$1 \times$ MF & 2 \\
$2 \times$ MF & 10 \\
$2 \times$ Asp & 1 \\
$2 \times$ MF, 1/2 Asp & 1 \\
Group NP & \\
Titre & No of subjects \\
$1 / 4 \quad$ MF & 1 \\
$1 / 2 \times$ MF & 6 \\
$1 \times$ MF & 8 \\
$2 \times$ MF & 12 \\
$1 / 4 \quad$ Asp & 1
\end{tabular}

MF-Micropolyspora faeni; Asp-Aspergillus fumigatus.

$M$ faeni and one to $A$ fumigatus initially; when restudied the subject who was positive to $A$ fumigatus was now positive to $M$ faeni. The titres of antibody to $M$ faeni were lower in 16, higher in six, and the same in 11 subjects (table 3 ). In general, subjects who had changed from positive to negative by the second study had relatively low titres in the initial study, and those who became positive had titres similar to those of the farmers who had remained positive (table 4).

Climatic conditions for the four summers (15 June15 August) preceding the precipitin studies are shown in table 5. Although the percentage of subjects who were precipitin positive varied from year to year, it did not correlate significantly with the number of days of rain or with the total rainfall during the previous summer.

Precipitin positive individuals in the second study were more often non-smokers $(p<0.01)$ and men $(p<0.05)$ and spent more hours in the barn than precipitin negative farmers $(p<0.01)$; these results are similar to those obtained in the first study. When the four groups of farmers were compared the consistently negative group were more likely to smoke $(p<0.01)$, and the consistently positive group spent more time in the barn $(p<0.01)$ and had larger farms $(p<0.05)$ see figure. Other variables tested (having or not having a hay dryer, hay conditioner, or silo and the quality of hay) did not differ between the groups.

Table 5 Climatic conditions of the four summers (15 June15 August) that preceded the data collection and the percentage of tested farmers positive for precipitins

\begin{tabular}{llll}
\hline & No of rain days & Quantity of rain $(\mathbf{m m})$ & $\%$ positive \\
\hline 1979 & 21 & 231.5 & 6.5 \\
1980 & 33 & 254.1 & 10.0 \\
1983 & 18 & 127.6 & 7.8 \\
1984 & 28 & 294.8 & 18.7 \\
\hline
\end{tabular}




\section{$\%$ OF SUBJECTS}

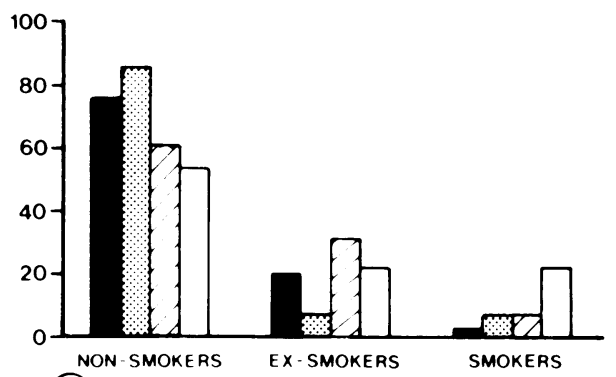

(A)
\% OF SUBJECTS

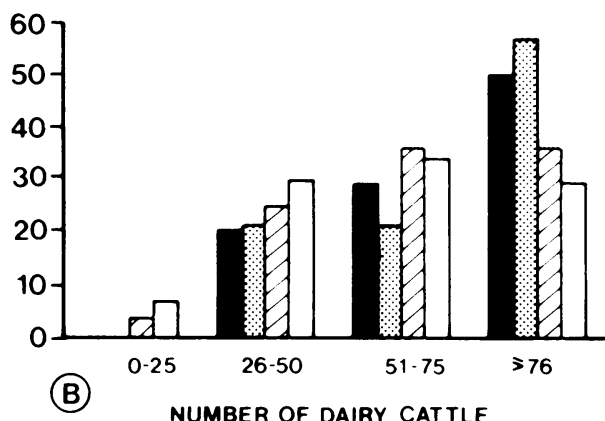

$\%$ OF SUBJECTS

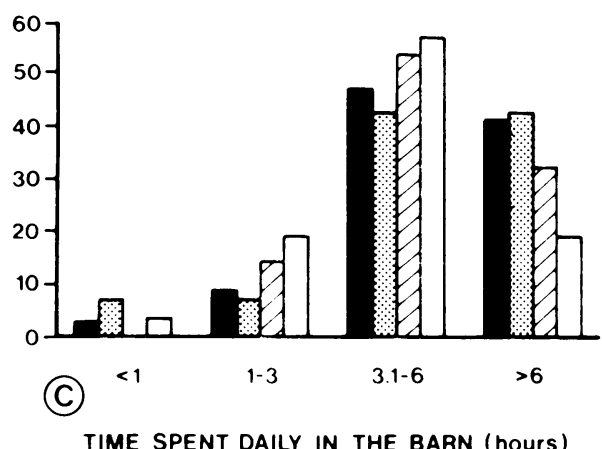

Respiratory symptoms (cough, sputum production, wheezing, dyspnoea, fever and chills) did not differ between the four groups. Five farmers who were restudied had been given a diagnosis of farmer's lung; in four this was made before the first study. Thus only one of the 445 farmers had acquired a diagnosis of farmer's lung during the four years between the two studies; he was precipitin positive in both studies.

\section{Discussion}

We were able to restudy 445 of the initial 888 subjects. Certain differences emerged when we compared the subjects who were restudied with those who were not. Not surprisingly, subjects who knew that they had a positive precipitin reaction at the first study were more likely to participate again. The other differences between the two groups are probably interrelated: women and younger and older subjects spent less time in the barn; older subjects had retired and some young subjects had left the farm.

Although our restudied group may not be representative of the overall farming population, several interesting observations may be made. The incidence of new cases of farmer's lung was very low (one case in four years), despite the fact that a high proportion of
Percentage of subjects for the four precipitin groups in relation to their smoking history $(A)$, number of dairy cattle $(B)$, and time spent daily in the barn during the winter months $(C)$. Serum precipitins in both studies;

precipitin positive in the first study and negative at follow up; negative in the initial study and positive at follow up; $\square$ negative in both studies. There were relatively more smokers among those who were precipitin negative in both studies $(p<0.01)$; subjects who were positive in both studies had larger farms $(p<0.05)$ and spent more time in the barn $(p<0.01)$

subjects with positive precipitin reactions participated the second time. This incidence of new cases of farmer's lung is lower than has previously been reported. ${ }^{70}$ The observation that smokers are more likely to remain precipitin negative agrees with our previous results ${ }^{1}$ and with the data of other workers. ${ }^{421} 22$ Also consistent with our previous data is the observation that precipitin positive subjects have a longer daily contact with the barn environment. The observation that larger farms are associated with being persistently precipitin positive is probably related to the fact that farmers with larger farms spend more time in the barn.'

Surprisingly, climatic variations did not explain the difference in the percentage of precipitin positive subjects between the study years. Farmer's lung and being precipitin positive are related to climate: dry countries have little or no farmer's lung whereas countries with a moist climate have a higher prevalence of precipitin positive individuals and of farmer's lung. The climatic variations between our study years may not have been of sufficient magnitude to contribute significantly to precipitin state. In addition, as precipitins may persist for a long time ${ }^{23}{ }^{24}$ analysis at a single time in the winter may not reflect the conditions of the previous summer. 
An interesting feature of this study was the fluctuation of the precipitin reaction from positive to negative in some subjects and vice versa. We did not use the most sensitive method of precipitin analysis available. We believe, however, that this less sensitive technique of double diffusion is justifiable for an epidemiological survey. In a previous study, using a sensitive ELISA tecinique, we found that only the high titres separated farmers from normal controls, and that the subjects with high titres were those with a positive result in the double diffusion test. ${ }^{25}$

The fluctuations in precipitin reaction we observed, coupled with previous ${ }^{1}$ and current observations that being precipitin positive is not age related, suggest that many dairy farmers in our region may become precipitin positive at least once in their lifetime. This may also be the case for lymphocytic alveolitis. In a previous study ${ }^{14}$ we found that 12 of 27 precipitin positive, symptomless dairy farmers had lymphocytic alveolitis (more than $22 \%$ of lymphocytes in the bronchoalveolar lavage fluid); two years later three of the 12 had a normal lavage fluid lymphocyte count whereas three of the 15 subjects with normal lavage fluid initially had developed lymphocytic alveolitis. ${ }^{17}$ Possibly many precipitin positive subjects have an increased lymphocyte count in their lavage fluid at some time. The fluctuant nature of precipitins and alveolitis could explain the lack of significant correlation between many variables of exposure and precipitins, and the occurrence of farmer's lung in previously seronegative farmers.

This work was supported by the Fondation JD Bégin of Laval University, and YC has a scholarship from the Fonds de la Recherche en Santé du Quebec.

\section{References}

1 Cormier Y, Bélanger J, Durand P. Factors influencing the development of serum precipitins to farmer's lung antigen in Quebec dairy farmers. Thorax 1985;40: $138-42$.

2 Ouchterlony O. Antigen-antibody reactions in gels. Acta Pathol Microbiol Scand 1953;32:231.

3 Roberts RC, Wenzel FJ, Emanuel DA. Precipitating antibodies in a midwest dairy farming population toward the antigen associated wth farmer's lung disease. J Allergy Clin Immunol 1976;57:518-24.

4 Gruchow HW, Hoffman RG, Marx JJ, Emanuel DA, Rimm AA. Precipitating antibodies of farmer's lung antigens in a Wisconsin farming population. Am Rev Respir Dis 1981;124:411-5.

5 Gump DW, Babbott FL, Holly C, Sylwester DL. Farmer's lung disease in Vermont. Respiration 1979;37: 52-60.

6 Marx JJ, Emanuel DA, Dovenbarger WV, Reinecke ME, Roberts RC, Treuhaft MW. Farmer's lung disease among farmers with precipitating antibodies to the thermophilic actinomycetes: a clinical and immunological study. J Allergy Clin Immunol 1978;62:185-9.
7 Smyth JT, Adkins GE, Lloyd M, Moore B, McWhite E. Farmer's lung in Devon. Thorax 1975;30:197-203.

8 Babbott FL, Gump DW, Sylwester DL, MacPherson BV, Holly C. Respiratory symptoms and lung function in a sample of Vermont dairymen and industrial workers. Am J Publ Health 1980;70:241-5.

9 Depierre A, Dalphisa JC, Pernet D, Dubiez A, Faucompré C, Breton JL. Epidemiological study of farmer's lung in five districts of the French Douba province. Thorax 1988;43:429-35.

10 Katila M-L, Mäntyjärvi RA. Prognostic value of precipitins for working ability in dairy farmers. Eur $J$ Respir Dis 1987;71(suppl):146-54.

11 Guernsey JR, Morgan DP, Marx JJ, Horvath EP, Pierce $P$, Merchant J. The prognostic significance of farmer's lung disease antibodies relative to measures of respiratory disease a Wisconsin dairy farming population [abstract]. Am Rev Respir Dis 1986;133:A256.

12 Pepys J, Jenkins PA. Precipitin test in farmer's lung. Thorax 1965;20:21-35.

13 Burrell R, Rylander R. A critical review of the role of precipitins in hypersensitivity pneumonitis. Eur $J$ Respir Dis 1981;62:332-43.

14 Fink JN. Hypersensitivity pneumonitis. J Allergy Clin Immunol 1973;52:309-17.

15 Cormier Y, Bélanger J, Beaudoin J, Laviolette M, Beaudoin R, Hébert J. Abnormal bronchoalveolar lavage in asymptomatic dairy farmers. Am Rev Respir Dis 1984;130:1046-9.

16 Moore VL, Pedersen GM, Hauser WCF, Fink JN. A study of lung lavage materials in patients with hypersensitivity pneumonitis: in vitro response to mitogen and antigen in pigeon breeders' disease. $J$ Allergy Clin Immunol 1980;65:365-70.

17 Cormier Y, Bélanger J, Laviolette M. Persistent bronchoalveolar lymphocytosis in asymptomatic farmers. Am Rev Respir Dis 1986;133:843-7.

18 Terho EO, Husman K, Vahlonen I, Mäntyjärvi RA. Serum precipitins against microbes in mouldy hay with respect to age, sex, atopy, and smoking of farmers. Eur J Respir Dis 1987;7(suppl):115-21.

19 Ferris BG. Epidemiology standardization project (July 1978). Am Rev Respir Dis 1978;118(suppl):1-120.

20 Grant IWB, Blyth W, Wardrop VE, Gordon RM, Pearson JCG, Mair A. Prevalence of farmer's lung in Scotland: a pilot survey. Br Med J 1972;i:530-4.

21 Warren CPW. Extrinsic allergic alveolitis: a disease commoner in non-smokers. Thorax 1977;32:567-9.

22 McSharry C, Banham SW, Boyd G. Effect of cigarette smoking on the antibody response to inhaled antigens and the prevalence of extrinsic allergic alveolitis among pigeon breeders. Clin Allergy 1985;15:487-94.

23 Braun SR, do Pico GA, Tsiatis A, Horvath E, Dickie HA, Rankin J. Farmer's lung disease: long-term clinical and physiological outcome. Am Rev Respir Dis 1979; 119:185-91.

24 Leblanc P, Bélanger J, Laviolette M, Cormier Y. Relationship between contact, alveolitis and clinical status in farmer's lung. Arch Intern Med 1986;146: 153-7.

25 Hébert J, Beaudoin J, Laviolette M, Beaudoin R, Bélanger J, Cormier Y. Absence of correlation between the degree of alveolitis and antibody levels to Micropolysporum faeni in exposed farmers. Clin Exp Immunol 1985;60:572-8. 